\title{
Iniciativas pioneiras do ensino de Desenho Industrial na FA-UFRGS
}

Maria do Carmo Curtis é Doutora em Design, Escola de Engenharia e Faculdade de Arquitetura, Universidade Federal do Rio Grande do Sul, 2017. Possui Mestrado em Teoria, HIstória e Crítica da Arte, Instituto de Artes, Universidade Federal do Rio Grande do Sul, 1998; Graduação em Educação Artística- Habilitação em Artes Visuais, Instituto de Artes, Universidade Federal do Rio Grande do Sul e Bacharelado em Desenho, Instituto de Artes, Universidade Federal do Rio Grande do Sul. É professora do Departamento de Design e Expressão Gráfica, Faculdade de Arquitetura, Universidade Federal do Rio Grande do Sul, desde 2010

<maria.curtis@ufrgs.br> ORCID: 0000-0001-7758-8496
Resumo $\mathrm{O}$ tema desse artigo é a gênese do processo de implantação do ensino de design no Rio Grande do Sul, tendo como referência o levantamento e análise de três iniciativas ocorridas na Faculdade de Arquitetura da Universidade Federal do Rio Grande do Sul (FA-UFRGS). É um desdobramento de uma tese de doutorado a respeito da implantação do design em âmbito local. A investigação foi feita a partir de dados obtidos por meio de entrevistas, da coleta $\mathrm{e}$ análise de documentos e de pesquisa bibliográfica. Constatou-se que o debate ocorrido no ambiente acadêmico da FA-UFRGS ao longo da década de 1960 estimulou a emergência de iniciativas pioneiras do ensino de desenho industrial. No entanto, fatores conjunturais e institucionais dificultaram o êxito de sua implantação. A discussão pode contribuir na compreensão dos motivos que explicam porque a implantação do ensino de design foi tão tardia no Rio Grande do Sul.

Palavras chave História do ensino de design, desenho industrial, Rio Grande do Sul. 
Liane Roldo é professora da UFRGS do Departamento de Materiais (DEMAT), orientadora de mestrado e doutorado no Programa de Pós-Graduação em Design Stricto Sensu (PGDesign) e coordenadora substituta do Laboratório de Design e Seleção de Materiais (LdSM). Desde 2008, bolsista PQ nível 2 do CNPq. Graduação em Engenharia Metalúrgica pela UFRGS (1994). Mestrado (1998) e doutorado (2004) em Engenharia na área de Ciência e Tecnologia dos Materiais - Programa de Pós-Graduação em Engenharia de Minas, Metalúrgica e de Materiais (PPGE3M) da UFRGS e pós-doutorado (2011) junto a FESB- University of Split, Croácia. Experiência na área de design de produto e seleção de materiais. Também atua nas áreas de análise de materiais metálicos, binômio percepção e materiais, biônica e ecodesign, bem como design para o bem-estar, educação e transdisciplinaridade, ecologia profunda e tecnologia.

<liane.roldo@ufrgs.br>

ORCID: 0000-0002-0301-8631

\section{Pioneer initiatives in teaching Industrial Design at FA-UFRGS}

Abstract The article explores the starting process of design education in Rio Grande do Sul State based on a survey and analysis of three initiatives at the Faculty of Architecture, Federal University of Rio Grande do Sul (FA-UFRGS). More specifically, it is a chapter of a doctoral thesis regarding the creation of the design in local scope. The tools used in this essay were: interviews, gathering and analysis of historic documents as well as literature review. It was verified that the academic debate that took place, in the 1960s, at FA-UFRGS stimulated pioneer actions in teaching industrial design. However, a combination of events and institutional factors hindered the successful implementation of the industrial design course. The present discussion may contribute to the understanding of why the implementation of design teaching was late in Rio Grande do Sul State.

Keywords History of design teaching, industrial design, Rio Grande do Sul. 


\section{Introdução}

Esta pesquisa sobre a gênese da implantação do ensino de design no Rio Grande do Sul parte da reflexão sobre diferentes níveis de compreensão do conceito de desenho industrial nos cenários internacional, nacional e local. A perspectiva histórica evidencia que a denominação dada aos fenômenos resulta das ' $n$ ' relações estabelecidas pelos sujeitos envolvidos em cada processo. A denominação acompanha as mudanças ocorridas no contexto socioeconômico e político, porque a atribuição de sentido é uma decorrência desses processos sociais. Isso explica empregar o termo "desenho industrial" no título desse artigo. A questão terminológica situa o período em que os fatos abordados ocorreram: meados do século XX.

Segundo Cara (2010: 16), no ambiente internacional, da década de 1970, a noção de "desenho industrial", que condiciona o conceito de projeto às questões formais e funcionais, começa a não ser suficiente para abarcar a abrangência com que o design pode atuar no capitalismo contemporâneo. Entretanto, no continente americano, nos anos 1960, o debate sobre desenho industrial ainda não atingira esse patamar crítico. No Brasil, o desenho industrial foi oportunamente conectado à industrialização e à tecnologia para fortalecer o projeto de modernização do Estado. Desse modo, observa-se um descompasso na compreensão do desenho industrial: enquanto no cenário internacional há uma crise de sentido do termo, no Brasil o significado de desenho industrial recém começava a ser discutido (CARA, 2010) e foi associado às áreas tecnológicas porque significavam um Brasil progressista (COUTO, 2008). Com efeito, meados do século XX é o período da implantação do ensino superior no campo enfocado, tema já discutido (SOUZA, 1996; MAGALHÃES, 1998; FREITAS, 1999; NIEMEYER, 2000; COUTO, 2008; LÉON, 2012). Somente nos anos 1980, com a consolidação do campo profissional, se fortalece no Brasil o debate sobre a necessidade de mudar a denominação e defende-se a "adoção oficial e institucional do termo design para denominar a profissão" (BRAGA, 2011). Importante notar que essa questão terminológica se reflete na implantação do ensino de design no RS, como será discutido adiante.

As iniciativas pioneiras de ensino do desenho industrial aconteceram no âmbito da Universidade Federal do Rio Grande do Sul, na Faculdade de Arquitetura (FA-UFRGS). O propósito desse artigo é analisar como se deu o processo histórico destas iniciativas e explicar, em parte, a institucionalização tardia do ensino do design em relação ao eixo Rio São Pauloํ. Para completar a delimitação, mencionam-se os principais participantes: Cláudio Araújo (1931-2016), Nelson Ivan Petzold (1931), Günter Weimer (1939). Envolvidos na prática e ensino da arquitetura, e na prática do desenho industrial, buscaram formalizar o ensino do desenho industrial nos anos 1960-70.

Pretende-se preencher uma lacuna do conhecimento sobre as condições sócio históricas que antecederam a implantação do ensino do design no cenário regional ao identificar, analisar e detectar relações existentes 
entre o ensino da arquitetura e a emergência de iniciativas do ensino de desenho industrial. A análise desse processo histórico visa apontar possíveis respostas e gerar novas indagações para contribuir à reflexão sobre o momento presente. A metodologia empregada para a realização da proposta foi pesquisa de campo (entrevistas semiestruturadas com participantes no processo histórico [Petzold, 2011]); pesquisa documental; pesquisa bibliográfica (FROTA, FUÃO, LEÃO, 2000; BOZZETTI, 2004; WEIMER, 2004; COUTO, 2008; CARA, 2010; BRAGA, 2011; BRAGA, 2016; MARQUES, 2012; MARQUES, 2016a; MARQUES, 2016b; MELLO, 2016; CURTIS, 2017).

\section{FA-UFRGS, ambiente propício ao ensino de desenho industrial}

Ambiente que sediou as iniciativas investigadas, a FA-UFRGS inicia esse item devido ao impasse que antecedeu sua inauguração e também os debates sobre o ensino de Arquitetura ao longo da década de 1960. Para facilitar a compreensão do encadeamento do processo histórico, o Quadro 1 serve como guia, expondo cronologicamente os principais pontos.

\begin{tabular}{|l|l|}
\hline 1952 & Inauguração da FA-UFRGS \\
\hline 1955 & Claudio Araújo gradua-se em Arquitetura, FA-UFRGS \\
\hline 1956 & Petzold gradua-se em arquitetura, FA-UFRGS \\
\hline 1959 & Claudio Araújo inicia docência na FA-UFRGS, na disciplina Composição Decorativa \\
\hline 1959 & ETC, Escola Técnica de Criação, MAM/RJ \\
\hline $\begin{array}{l}\text { Anos } \\
60\end{array}$ & Desenho Industrial associado ao projeto de modernização do País \\
\hline 1962 & Petzold inicia docência na FA-UFRGS, na disciplina Grandes Composições \\
\hline 1962 & ESDI/RJ marca o início do ensino superior de desenho industrial no Brasil \\
\hline 1962 & FAUUSP inicia sequência de desenho industrial na graduação de arquitetura \\
\hline 1962 & Parceria Bornancini e Petzold na indústria local \\
\hline 1962 & Debate do ensino na FA-UFRGS | Organização do currículo de arquitetura em 3 ciclos \\
\hline 1963 & Weimer gradua-se em arquitetura, FA-UFRGS \\
\hline 1965 & $\begin{array}{l}\text { Petzold solicita transferência de Grandes Composições e passa a compartilhar docência em } \\
\text { Composição Decorativa com Claudio Araújo }\end{array}$ \\
\hline 1966 & $\begin{array}{l}\text { Claudio Araújo viaja a São Paulo| Frequenta curso sobre comunicação, visita escritórios de } \\
\text { desenho industrial e fábricas de mobiliário, Contato com FAU-USP }\end{array}$ \\
\hline 1966 & Primeira Semana de Estudos na FA-UFRGS | Avaliação de 1962 \\
\hline 1966 & $\begin{array}{l}\text { INICIATIVA 1 | Curso de especialização de Desenho Industrial para egressos de Engenharia e } \\
\text { Arquitetura/ FA-UFRGS }\end{array}$ \\
\hline 1967 & Weimer especializa-se em Desenho Industrial pela HfG Ulm \\
\hline 1968 & Reforma Universitária Brasileira \\
\hline 1968 & Seminário para nova estrutura de ensino na FA-UFRGS| Arquitetura do objeto \\
\hline 1968 & Weimer inicia docência na FA-UFRGS em Composição Decorativa \\
\hline 1968 & $\begin{array}{l}\text { INICIATIVA 2 | Transformar disciplina Composição Decorativa em Desenho Industrial- } \\
\text { Graduação em Arquitetura/ FA-UFRGS }\end{array}$ \\
\hline $\mathbf{7 0}$ & $\begin{array}{l}\text { INICIATIVA 3 | Instituir disciplina optativa de Desenho Industrial- Graduação em Arquitetura / } \\
\text { FA-UFRGS }\end{array}$ \\
\hline & \\
\hline 1960
\end{tabular}

Quadro 1. Gênese da implantação do ensino de design no Sul, 1952-1970 Fonte: NIEMEYER, 2000; FROTA, FUÃO, LEÃO, 2000; WEIMER, 2004; BOZZETTI, 2004; COUTO, 2008; CARA, 2010; PETZOLD, 2011; MELLO, 2016; MARQUES, 2016; CURTIS, 2017 


\section{Inauguração da FA-UFRGS: marco da cultura projetual}

De acordo com Bozzetti (2004), a inauguração da FA-UFRGS (1952) constitui marco pioneiro na cultura projetual do Rio Grande do Sul, pois representa uma etapa que assinala o início da autonomia do ensino da Arquitetura em relação às áreas correlatas. Desde 1945, o ensino da Arquitetura era oferecido no Instituto de Belas Artes (IBA) e na Escola de Engenharia (BERED, 2000; BOZZETTI, 2004; MELLO, 2016). Segundo Mello (2016: 84), na época o IBA estava desvinculado da Universidade, por isso era viável a existência de dois cursos de Arquitetura. Como modelo pedagógico, o curso de Arquitetura do IBA pautava-se pelo "padrão federal" ${ }^{2}$ representado pela Faculdade Nacional de Arquitetura da Universidade do Brasil (FNA/RJ), enquanto a Escola de Engenharia seguia a Politécnica de São Paulo.

A partir de 1948, o IBA foi incorporado à Universidade, o que gera um problema: a instituição passa a oferecer dois cursos da mesma graduação. Naquele ano foi promulgada a lei estadual no 418 determinando a "fusão" dos cursos de Arquitetura. 0 andamento desse processo instaurou um impasse no meio acadêmico ${ }^{3}$ devido a diferentes concepções sobre Arquitetura, subjacentes em cada curso. Na visão dos engenheiros, a Arquitetura era um "ramo" da Engenharia, logo, domínio da técnica. Por sua vez, a formação proposta pelo Belas Artes (segundo o "padrão federal") considerava a Arquitetura como uma "secção" da arte, portanto, domínio da composição (MELLO, 2016: 345).

Edgar Graeff, professor do IBA, membro do Instituto dos Arquitetos do Brasil (IAB/RS ${ }^{4}$ ), defende a criação de uma Faculdade de Arquitetura autônoma, contrapondo-se à proposta dos engenheiros, que defendiam um Instituto de Arquitetura submetido à Escola de Engenharia. Mello (2016) resume a arguição de Graeff em três pontos: i) a defesa da arquitetura como arte; ii) a oposição análise - síntese; iii) a centralidade da composição na formação em Arquitetura. Se a argumentação converge com o padrão federal, valorizando aspectos formais, por outro lado Mello (2016) nota que a centralidade da composição, referida por Graeff, não se reduz à seleção e articulação de elementos físicos. A composição é um processo mental que articula diferentes campos disciplinares para materializar a obra ${ }^{5}$ arquitetônica. Definição que demonstra como sua tese transcende a concepção acadêmica proveniente do modelo Beaux-Arts.

\footnotetext{
A composição - disciplina e método - deveria, enfim, organizar o processo didático- pedagógico da Faculdade de Arquitetura, colocando-se como centro da formação. (...) Sua manifestação, inserida num momento de conflito pela delimitação e domínio do campo, era, como visto, prescritiva. Sua argumentação não se baseava apenas num "espaço de experiências", mas representava também um "horizonte de expectativas" em relação ao ensino e ao futuro da profissão (MELLO, 2016, p. 345).
} 
Em meio ao impasse, a Faculdade de Arquitetura foi instalada em 1952, prevalecendo a tese defendida pelo IBA. Mas, na análise de Mello, sua inauguração resultou de "uma acomodação entre opostos conciliados". De um lado, optou-se pela autonomia do ensino de Arquitetura em relação à Engenharia usando o padrão federal como referência. Por outro, o corpo docente foi composto majoritariamente por professores engenheiros e catedráticos da Escola de Engenharia (MELLO, 2016).

Ainda que relativa, a conquista de uma sede própria e a orientação pelo padrão federal no ensino de Arquitetura repercute positivamente na gênese do ensino de Design. Segundo Bozzetti (2004: 33), a autonomia do novo núcleo de arquitetura viabiliza o ensino superior aos "artista- técni-

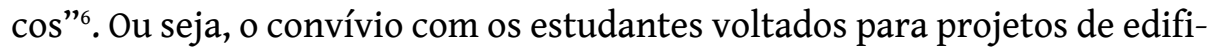
cações, aproxima os "candidatos a designers" do conhecimento que buscavam no ensino formal.

\section{Anos 1960: Debates sobre o ensino da arquitetura na FA-UFRGS}

Os anos 1960 foram palco de debates sobre o ensino na FA-UFRGS, período em que a argumentação de Graeff foi retomada. Em 1962, o currículo do curso foi dividido em três ciclos: básico, preparação profissional e tese. Mas manteve estrutura similar ao padrão federal. Ou seja, a disciplina "Composição" permaneceu como núcleo da formação, apresentando maior carga horária em relação às demais disciplinas e submetendo-as à sua lógica. Em 1966, durante a "Primeira semana de estudos", as mudanças decorrentes da proposta de 1962 foram avaliadas, verificando-se que não alteraram o ensino.

Em 1968, o contexto sociopolítico acadêmico estava particularmente tumultuado devido à Reforma Universitária. Os estudantes publicaram "Nosso Ensino é uma Farsa", um manifesto que resultou no "Seminário de estudos para uma nova estrutura de ensino". No relatório final do seminário, a capacidade de projetar é considerada a habilidade central da formação em Arquitetura e a tecnologia e as Ciências Sociais foram avaliadas como "conteúdos instrumentais, meios de ação, e não fins". A novidade é a concepção de que objetos, edifícios e cidades são artefatos que se distinguem somente na escala, pois é possível projetá-los por meio do mesmo processo mental de síntese. Essa concepção é inserida no currículo na etapa de preparação profissional, classificada em três níveis: desenho do objeto, edificação e urbanismo (Seminário de Estudos para uma nova estrutura de ensino, 1968 apud MELLO, 2016, p. 252). Mas a proposta de nova estrutura de ensino não vigorou logo. Voltou-se a debate-la em 1969, porém alterações significativas só foram implantadas na década seguinte na FA-UFRGS (MELLO, 2016, p. 253). 


\section{Iniciativas de ensino do desenho industrial}

A seguir, apresenta-se os dados obtidos sobre os protagonistas que tentaram implantar o ensino de Desenho Industrial no cenário local e respectivas iniciativas idealizadas na FA-UFRGS.

\section{Protagonistas das iniciativas pioneiras do ensino de desenho industrial}

Cláudio Luís Gomes de Araújo inicia sua formação em arquitetura na UFRGS no curso de Arquitetura na Escola de Engenharia em 1950, portanto antes da fusão. Inicialmente, as aulas eram compartilhadas com as demais engenharias e o curso de Arquitetura, orientado por Eugene Steinhof ${ }^{7}$. Araújo já cursava o segundo ano quando as aulas começaram a ocorrer em conjunto. Em retrospectiva, ele avalia que o ensino oriundo do Belas Artes o preparou melhor quanto à teoria, reflexão conceitual e consciência política, por outro lado, a Engenharia contribuiu nas questões técnicas. Quanto à prática profissional, "o projeto e o fazer" arquitetura resultaram da "vivência e convivência com veteranos que exerciam o ofício" e da relação com os colegas, frequentando os escritórios de arquitetura (ARAÚJO apud MARQUES, 2016b). Ingressou na FA- UFRGS como Instrutor de Ensino da disciplina de Composição Decorativa em 1958 e atuou de 1959 a 1968. Sua docência caracterizou-se por desenvolver exercícios projetuais de elementos aplicados à Arquitetura, como vasos sanitários, lavatórios, maçanetas, mobiliário e utensílios. Desse modo, ele direcionou o escopo da disciplina do currículo de arquitetura para o desenho industrial ambientado na arquitetura. Em parte, esse direcionamento foi amparado na sequência de Desenho Industrial da FAU-USP (MARQUES, 2016a).

No âmbito da cultura projetual, Araújo atuou pela classe profissional como presidente do IAB/RS. Segundo Marques (2016b), sua gestão em 1966/67 foi um dos períodos mais ativos sob o ponto de vista cultural, tendo organizado o IV Salão de Arquitetura do Rio Grande do Sul e inaugurada a galeria de arte do IAB. Além disso, Araújo foi membro da Associação Brasileira de Desenho Industrial (ABDI), posição que o tornou elo de ligação entre o ambiente local e o eixo Rio- São Paulo (BRAGA, 2016, p.100).

Em 1966, Araújo esteve em São Paulo representando a FA-UFRGS no curso "Problemas de Comunicação de Massa", promovido pela ABDI e ministrado por Umberto Eco (1932-2016). Ele também participou do curso “Teoria da Informação", oferecido por Décio Pignatari (1927-2012). Também foi significativo a cultura projetual seu contato com Luiz Gastão de Castro Lima, docente na sequência do Desenho Industrial na FAU-USP. Na ocasião, Araújo acompanhou exercícios de atelier de projeto na instituição e, mais tarde, a convite de Araújo, Luiz Gastão e um auxiliar ministraram um curso sobre a utilização de fibra de vidro na produção de mobiliário na FA-UFRGS. Além de contatos acadêmicos, a viagem a São Paulo propiciou visitar escritórios e empresas ligadas ao Desenho Industrial, como a Form-Inform e a FORMA, indústria vinculada à Knoll International, dedicada à fabricação de mobiliário assinado por arquitetos consagrados internacio- 
nalmente ${ }^{8}$; a loja Mobilia Contemporânea e as lojas das indústrias OCA e L'Atelier (ARAÚJO, 1967 apud MARQUES, 2016a).

Nelson Ivan Petzold ingressa no curso de arquitetura em 1952, ano da fusão dos cursos, e frequenta as aulas no Castelinho, próximo ao Observatório9. Em 1954, começa a trabalhar em escritório de arquitetura, quando constata sua predileção pela "microarquitetura" 10 ao dedicar-se a maquetes e detalhes como esquadrias e telhados (PETZOLD, 2011). Em 1961, reingressa na FA- UFRGS como Instrutor de Ensino na disciplina Grandes Composições. No ano seguinte, é convidado por Bornancini ${ }^{11}$ a colaborar em um projeto de fogão na Wallig, empresa metalúrgica local, iniciando uma parceria de cinco décadas no Design Industrial (PETZOLD, 2008).

Em 1965, Petzold solicita sua transferência docente para a disciplina de Composição Decorativa, pois se sentia "um pouco deslocado da área de projetos, porque já trabalhava com objetos na Arquitetura de Interiores. Foi uma questão de me ajustar à escala" (PETZOLD, 2011). Araújo já desenvolvia propostas de análise de produtos como atividade de ensino na disciplina de Composição Decorativa. Como exemplo dessa atividade pedagógica, Petzold cita o exame de uma cadeira projetada na Bauhaus ou por um designer norte americano, como Charles Eames. 0 enfoque da análise era avaliar o produto observando aspectos funcionais ou compositivos para verificar possibilidades de alterações, como os materiais empregados ou a configuração formal (PETZOLD, 2011). Em relato sobre a formação na FA-UFRGS, Bozzetti (2004, p.35) destaca sua experiência na disciplina Composição Decorativa, cujos professores, "ampliando a ementa, abriam um generoso espaço para o estudo do Design de Produto - essencialmente de mobiliário -com ênfase em cartazes e embalagens".

Günter Weimer ingressou na FA-UFRGS em 1959, graduando-se em 1963. Obteve uma bolsa de estudos concedida pelo governo alemão e cursou Especialização em Desenho Industrial na HfG-Ulm, de 1965 a 67. Sua atuação docente na FA-UFRGS inicia a convite de Araújo para integrar a disciplina Composição Decorativa em 1968 (WEIMER, 2004). Na graduação, atuou em Geometria dos Poliedros; Teoria das Cores; Luzes e Cores; Desenho Geométrico e Percepção; Desenho Técnico para Arquitetura ${ }^{12}$.

Em relação à prática projetual, Weimer $(2004$, p.82) relata que foi contratado por Manlio Gobbi ao final dos anos 1960 para trabalhar numa pequena fábrica especializada em móveis de escritórios, em conjunto com os arquitetos Carlos Eduardo Warhlich e Armênio Wendhausen ${ }^{13}$. A equipe projetou a MaGnalínea, linha de mobília cuja funcionalidade permitia um grande número de combinações. Os catálogos e o logotipo do produto ficaram a cargo de Norberto Bozzetti (GOBBI, 2008, p.28). Weimer relata que participou de outros projetos na indústria pesada e empresas de porte, nos quais ele enfrentou problemas de "acidentes devido à fragilidade resultante da economia dos custos de produção". Por isso, decide abandonar o projeto de produto e dedicar-se à pesquisa e à docência universitária (WEIMER, 2004, p.83). Dando continuidade à sua titulação acadêmica, cursou o Mestrado em História da Cultura (PUCRS, 1981) e o Doutorado em Arquitetura e Urbanismo (FAU-USP, 1990). 


\section{Programação Paralela de Desenho Industrial}

Petzold narra uma tentativa de "oficializar o ensino de Desenho Industrial" na FA-UFRGS em 1966. A proposta era voltada principalmente a egressos de Arquitetura e Engenharia, concebida na modalidade Especialização, aproveitando uma possível demanda complementar entre as duas graduações. A base curricular apoiava-se nas disciplinas dos cursos de Arquitetura e Engenharia e um núcleo de disciplinas de Desenho Industrial. o pressuposto era aproveitar a estrutura já existente na instituição assim como a complementaridade curricular. Em tese, os engenheiros cursariam as disciplinas de arquitetura e os arquitetos, as da engenharia (PETZOLD, 2011).

A proposta intitulava-se "Programação Paralela de Desenho Industrial para o Curso de Arquitetura da Faculdade de Arquitetura da UFRGS"14. Günter Weimer, na condição de egresso da FA-UFRGS e discente da HfG-Ulm, seria encarregado da justificativa e da elaboração de uma introdução teórica aos aspectos históricos, destacando a "ligação do Arquiteto com os movimentos mais importantes no campo do Desenho Industrial”. Petzold estaria incumbido dos aspectos legais da implantação do curso, visando sua conformidade às normas institucionais da Universidade (PROGRAMAÇÃO PARALELA, 1966).

Segundo Petzold (2011), a duração do curso de especialização seria de 4 anos. A partir do 20 semestre, o programa seria estruturado por temas de complexidade crescente para "se adequar ao Desenho Industrial". A organização e a coordenação ficariam a cargo dos professores de Composição Decorativa (Cláudio Araújo e Nelson Petzold) e de professores da FA-UFRGS cujo interesse sobre Desenho Industrial fosse manifesto em trabalhos e cursos relativos ao assunto [Claudio Araújo, Nelson Petzold, Günter Weimer, Fernando de Azevedo Moura ${ }^{15}$, Frarde]. Professores de outras unidades da UFRGS poderiam colaborar no desenvolvimento da Programação Paralela, dentre os quais é possível citar José Carlos Bornancini. Técnicos e profissionais não ligados à UFRGS também poderiam contribuir por meio de "palestras ou ciclo de palestras". Entretanto, Petzold (2011) relata que a Programação Paralela não interessou à Universidade, pois em 1966 o foco institucional era o ensino de graduação.

Desenho industrial: uma disciplina na graduação de Arquitetura, 1968

Outra iniciativa de ensino em Desenho Industrial acontece dois anos depois na FA-UFRGS. Günter Weimer (2004) lembra que ao retornar de sua especialização em Desenho Industrial na Escola de Ulm, em 1968, foi convidado pelo professor Cláudio Araújo para integrar o corpo docente da Faculdade de Arquitetura. Sua intenção (de longa data) era transformar a Decoração de Interiores ${ }^{16}$ em uma disciplina de Desenho Industrial. Assim, eles iniciaram o trabalho estruturando os novos conteúdos. Porém, conforme já mencionado, as condições sociopolíticas estavam conturbadas no Brasil e repercutiam no ambiente acadêmico. 
Weimer cogita então a possibilidade de que a "onda de insatisfação generalizada que se abatia sobre as universidades europeias" tinha fomentado uma revanche por parte das autoridades federais, que atuaram de modo mais violento do que em 1964. Foi "deflagrada nova onda de cassações e de repressão" na Universidade. A Reforma Universitária Brasileira de 1968 foi "centralizadora e policialesca, visava colocar um freio" no desagrado do ambiente acadêmico. De fato, a situação culminou com o afastamento de muitos professores da FA-UFRGS, como relata Claudio Araújo.

\footnotetext{
Pedi meu desligamento da UFRGS, porque lecionar tornou-se uma coisa problemática durante a ditadura militar. Nós fomos resistindo até onde deu. Eu atuava no IAB, na faculdade e no escritório. O IAB também enfrentou problemas. Prenderam alguns colegas sem justificativa. $\mathrm{O}$ momento era muito tumultuado. Eu chefiava o Departamento de Projetos. (...) quando a crise serenou, eu já estava cansado, (...) aguardei a escolha do novo chefe de departamento e resolvi abandonar a faculdade e ficar só com o escritório (ARAUJO, 2000 apud FROTA; FUÃO; LEÃO, 2000).
}

Nesse quadro problemático, o plano de transformar a disciplina de Composição Decorativa em Desenho Industrial teve que ser adiado (WEIMER, 2004).

\section{Desenho Industrial: disciplina optativa}

Segundo Weimer (2004), no começo da década de 1970 o ambiente acadêmico estava mais favorável à implantação do ensino de Desenho Industrial. A administração da UFRGS pretendia instalar um curso de Desenho Industrial. Mas ele considerou a ideia precipitada pois, na sua avaliação, faltavam condições necessárias ao projeto de ensino. Principalmente professores qualificados, instalações apropriadas e oficinas equipadas para o desenvolvimento dos trabalhos. Ele cita que, na época, havia apenas uma marcenaria bem montada e uma oficina de gesso precariamente equipada. Outro argumento se ampara no âmbito socioeconômico. Weimer alega que na Alemanha, altamente industrializada, formavam-se cerca de 50 designers em "pouco mais de uma dezena de escolas, enquanto no país, só na cidade de Curitiba, eram formados mais de 150." Ele avalia que a formação massiva de profissionais mal preparados não seria ética. Recomenda então que seria melhor começar de modo mais modesto, instituindo uma disciplina optativa de Desenho Industrial na graduação de arquitetura. Mas faltou apoio dos estudantes já sobrecarregados com as tarefas curriculares e ainda inconformados com os rumos da Universidade e do país. Weimer (2004) narra que após dois ou três semestres o projeto de instituir uma disciplina de Desenho Industrial na graduação em Arquitetura foi cancelado temporariamente ${ }^{17}$. 


\section{Discussão}

O estudo do processo histórico da implantação do Design no Sul indica que a compreensão do Desenho Industrial ainda era muito incipiente em relação ao eixo Rio-São Paulo em meados dos anos 1960 (CURTIS, 2017). Isso dificultou efetivar as iniciativas emergentes do ensino de desenho industrial na FA-UFRGS. Cabe lembrar que a formação em Arquitetura, atividade profissional correlata, inicia sua autonomização no ensino da arte e engenharia no começo da década anterior, em 1952. É compreensível que nos anos 1960, as iniciativas de ensino do desenho industrial tenham enfrentado tantas dificuldades uma vez que a cultura projetual desta atividade ainda estava se constituindo no âmbito local. Assim, dentre os fatores conjunturais que repercutem negativamente na gênese do ensino do design no RS aponta-se o (1) descompasso da compreensão do desenho industrial nos diferentes níveis e (2) a Reforma Universitária Brasileira, 1968.

0 primeiro fator remete à diferença na compreensão do Desenho Industrial nos âmbitos internacional, nacional e local. O descompasso existente entre a compreensão do Desenho Industrial no Brasil em relação ao cenário internacional teve implicações em nível local. Essa interdependência evidencia a importância de atingir uma compreensão mais efetiva da prática projetual do Desenho Industrial no cenário rio-grandense. Um episódio relacionado ao ensino de Arquitetura pode ser interpretado positivamente nesse sentido: a arguição de Edgar Graeff (1948) favorável à autonomia do curso de Arquitetura. Quando define o termo "composição" numa concepção que transcende à questão puramente formal, mesmo que ele esteja se referindo ao padrão federal, sua argumentação se alinha com o teor do debate internacional relativo à crise de sentido do Desenho Industrial, o qual buscava superar o binômio forma/função.

Foi custoso ao ambiente acadêmico da FA-UFRGS atingir uma autonomia plena. Mesmo na década de 1960 a análise do debate sobre o ensino de Arquitetura mostra que as reformas sugeridas não foram significativas a ponto de desvincular o ensino da Arquitetura do formalismo herdado das "Beaux Arts" (MELLO, 2016). Assim, o próprio ensino de Arquitetura, ambiente sede das iniciativas pioneiras de ensino do Desenho Industrial, ainda estava em questionamento nos anos 1960.

A Reforma do Ensino Universitário em 1968, fator vinculado à esfera sociopolítica, resultou na ênfase em áreas tecnológicas, em detrimento das humanas (COUTO, 2008), e gerou um clima de insatisfação acadêmica devido à onda de cassações e à repressão (ARAÚJO apud FROTA, FUÃO, LEÃO, 2000; WEIMER, 2004). Cláudio Araújo manifestou seu desagrado quanto ao autoritarismo que se instalou no ambiente acadêmico a ponto de se desligar da Universidade Federal do Rio Grande do Sul em 1968. No início dos anos 1970, esse fator ainda vigorava na Universidade, como verifica-se na tentativa frustrada de Weimer de implantar uma disciplina optativa de Desenho Industrial. 
Após destacar os fatores conjunturais, a discussão passa a tratar dos fatores específicos relacionados ao processo histórico investigado. O Quadro 2 aponta os principais elementos que constituem as potencialidades e fragilidades vivenciadas pelos protagonistas do processo no âmbito institucional da Universidade.

Os debates sobre o ensino na FA-UFRGS, embora não tenham conseguido alterar a estrutura do ensino de arquitetura (MELLO, 2016), foram importantes para o processo em estudo. Duas das três iniciativas coincidem cronologicamente com o movimento na comunidade acadêmica: 1966 e 1968. O que permite conjecturar que o debate interno na FA-UFRGS pode ter favorecido aos docentes mobilizarem-se quanto a implantação da atividade projetual da "microarquitetura".

\begin{tabular}{|l|l|}
\hline \multicolumn{1}{|c|}{ Potencialidades } & \multicolumn{1}{c|}{ Fragilidades } \\
\hline $\begin{array}{l}\text { Os debates sobre ensino ocorridos na FA-UFRGS } \\
(1962,1966 \text { e 1968) }\end{array}$ & $\begin{array}{l}\text { Desinteresse institucional pelo ensino } \\
\text { especializado }\end{array}$ \\
\hline $\begin{array}{l}\text { Docentes da arquitetura com visão favorável ao DI } \\
\text { e que atuavam profissionalmente em desenho } \\
\text { industrial }\end{array}$ & \begin{tabular}{l} 
Falta de recursos humanos preparados \\
\cline { 2 - 2 }
\end{tabular} \\
\hline
\end{tabular}

Quadro 2. Fatores específicos do processo de implantação de ensino de DI na FA-UFRGS durante a década de 1960

Os docentes de Arquitetura que protagonizaram as iniciativas estudadas contribuíram para estabelecer uma rede de contatos e colaboradores que foram criando as condições necessárias à uma compreensão mais efetiva do significado da atividade projetual do Desenho Industrial. Compreensão que foi esclarecendo a prática projetual do desenho Industrial e favorecendo a implantação de uma cultura local do Desenho Industrial.

Nesse prisma, a atuação de Araújo na FA-UFRGS, direcionando o ensino do Desenho Industrial ambientado na Arquitetura, estabelecendo relações com o meio cultural de São Paulo, devido a sua ligação com a ABDI e trabalhando em prol da classe profissional no IAB/RS, foi propícia à cultura local do Desenho Industrial, concretizando ações que promoveram o conhecimento sobre o campo, como a conferência no IAB/RS e FA-UFRGS de Umberto Eco, assim como o curso de Décio Pignatari na FA-UFRGS. Assim como destaca-se a ação de Petzold que também fortalece a cultura local, porém num sentido inverso, ou seja, favorecendo ao eixo Rio- São Paulo conhecer e valorizar o Desenho Industrial concebido e produzido no RS, pela excelência de sua performance profissional (em parceria com Bornancini) no design industrial local (CURTIS, 2017, p.198-201).

Prosseguindo a discussão, o Quadro 3 apresenta uma análise comparativa entre as iniciativas, a partir dos critérios Estrutura proposta, Relação com professores, Obstáculos que dificultaram a implantação. A primeira iniciativa de ensino de Desenho Industrial na FA-UFRGS foi concebida como curso de especialização, portanto como Pós-graduação. A estrutura 
do curso era orientada por temas de complexidade crescente. Ou seja, a abordagem pedagógica vincula o nível de complexidade tecno-temática ao grau de inserção discente no curso. Diretriz que permanece atual em cursos que se dedicam ao ensino de projeto. Explorar a complementaridade da formação em arquitetura e engenharia foi uma opção viável para o ensino de Desenho Industrial a partir de estruturas existentes na Universidade. Nesse sentido, a parceria Bornancini/Petzold é exemplo de que essa complementaridade pode habilitar à prática projetual, considerando a demanda pelo fator tecnológico no contexto industrial daquela época (CURTIS, 2017).

\begin{tabular}{|c|c|c|c|}
\hline & 1 PETZOLD/ ARAÚJO- 1966 & 2 ARAÚJO/ WEIMER- 1968 & 3 Günter WEIMER- anos 1970 \\
\hline \multirow{3}{*}{ 尝 } & $\begin{array}{l}\text { For mação complementar em DI para } \\
\text { egressos em arquitetura e } \\
\text { engenharia; } \\
\text { Duração de } 8 \text { semestres }\end{array}$ & \multirow[t]{2}{*}{$\begin{array}{l}\text { Transformar a disciplina de } \\
\text { Composição Decorativa em } \\
\text { disciplina de Desenho } \\
\text { Industrial }\end{array}$} & \multirow[t]{2}{*}{$\begin{array}{l}\text { A precariedade da estrutura oficinal e } \\
\text { falta de professores qualificados, indica } \\
\text { ser mais realista propor uma disciplina } \\
\text { em vez de curso }\end{array}$} \\
\hline & $\begin{array}{l}\text { Curso organizado por temas de } \\
\text { complexidade crescente, similar às } \\
\text { disciplinas de Projeto/ Arquitetura }\end{array}$ & & \\
\hline & $\begin{array}{l}\text { Curso de Especialização orientado a } \\
\text { egressos de Arquitetura e Engenharia }\end{array}$ & $\begin{array}{l}\text { Disciplina na Graduação de } \\
\text { Arquitetura }\end{array}$ & $\begin{array}{l}\text { Disciplina optativa na Graduação de } \\
\text { Arquitetura }\end{array}$ \\
\hline 高 & $\begin{array}{l}\text { Curso organizado com docentes } \\
\text { interessados em DI e colaboração de } \\
\text { colegas de outras unidades, técnicos } \\
\text { e profissionais não ligados à UFRGS }\end{array}$ & $\begin{array}{l}\text { Günter Weimer } \\
\text { Cláudio Araújo }\end{array}$ & $\begin{array}{l}\text { Weimer é crítico em relação à } \\
\text { competência dos colegas para ministrar } \\
\text { disciplinas de DI }\end{array}$ \\
\hline 。ั̆ & $\begin{array}{l}\text { A UFRGS não tinha interesse em } \\
\text { Especialização durante a década de } \\
1960 \text {, priorizando a Graduação }\end{array}$ & $\begin{array}{l}\text { Reforma Universitária de } \\
1968 \text { leva ao afastamento } \\
\text { de professores }\end{array}$ & $\begin{array}{l}\text { Discentes da arquitetura } \\
\text { sobrecarregados, sem tempo para a } \\
\text { disciplina de DI e estavam inconformados } \\
\text { com a situação política nacional }\end{array}$ \\
\hline
\end{tabular}

Quadro 3. Iniciativas de ensino de Desenho Industrial propostas na FA-UFRGS Fonte: WEIMER, 2004; PETZOLD, 2011; MARQUES, 2016a

Incluir na justificativa da Programação Paralela uma introdução sobre a ligação histórica do arquiteto com aspectos do Desenho Industrial revela consciência dos propositores da afinidade de competências entre arquitetos e designers. Em parte, essa consciência pode decorrer da formação em Arquitetura e da atuação profissional em Desenho Industrial dos três protagonistas. No entanto, a administração da Universidade não efetivou a Programação Paralela de Desenho Industrial para o Curso de Arquitetura da FA-UFRGS, alegando que o ensino de graduação era a prioridade institucional. Possivelmente, a proposição de Petzold e Araújo (1966) seria uma oportunidade aos "artistas-técnicos", conforme terminologia de Bozzetti (2004), para aprimorar sua qualificação profissional.

Em 1968, o ambiente institucional estava impregnado pela Reforma Universitária, "centralizadora e policialesca" que levou a FA-UFRGS a uma instabilidade, pois até os "novos professores contratados a esmo" foram incapazes de suportar (WEIMER, 2004, p.81). Nesse clima de insatisfação, o debate na FA-UFRGS gera o "Seminário de estudos para uma nova estrutura de ensino", que propõe como resultado o ensino da Arquitetura em três níveis: desenho do objeto, edificação e urbanismo. A novidade ${ }^{18}$ é a concepção 
de que objetos, edifícios e cidades são artefatos que se distinguem somente na escala, pois pode-se projetá-los por meio do mesmo processo mental de síntese (MELLO, 2016).

Nessa discussão, cabe destacar que subjacente a essa proposta, detecta-se o pensamento de que o Desenho Industrial seria um "setor" da Arquitetura, assim como, no passado, a Arquitetura fora interpretada como "uma secção da arte" ou "ramo da Engenharia". Possivelmente, a natureza múltipla e afim destas atividades projetuais (design, arquitetura, arte, engenharia) pode suscitar uma espécie de encadeamento da formação profissional, na qual as carreiras que se institucionalizaram primeiro exercem uma ascendência sobre as mais recentes. Essa relação ajuda a compreender porque o ensino da Arquitetura estava polarizado entre a arte e a engenharia no contexto local em 1945. E talvez explique porque a FA-UFRGS propõe "desenho do objeto" como nível de ensino na graduação de Arquitetura, em 1968. Essa "novidade" no ensino da Arquitetura, entretanto, não foi efetivada.

Ainda em 1968, a iniciativa conjunta de Araújo e Weimer, de transformar a disciplina de Composição Decorativa em Desenho Industrial, foi adiada após o afastamento do primeiro devido aos problemas que a ditadura militar causava no ambiente acadêmico.

A análise da proposição de Weimer, nos anos 1970, revela uma postura diferente quanto aos parâmetros para conceber uma proposta de ensino daquelas empregadas por Petzold e Araújo (1966). Weimer prioriza as especificidades do conteúdo em vez de otimizar as estruturas existentes. Provavelmente, tal abordagem estava ancorada em sua experiência discente na Alemanha. Em 1967 ele retorna de HfG Ulm com o título de Especialista em Desenho Industrial, qualificação que o torna mais prudente que seus predecessores em relação ao ensino da prática projetual. Seu julgamento relativo à industrialização demonstra uma compreensão crítica da realidade nacional ao notar a desproporção existente entre a capacidade de absorção do profissional de Desenho Industrial pelo mercado interno, comparando a quantidade de formandos no Brasil e na Alemanha. Assim, diante da ideia de um curso de Desenho Industrial, defendido pela UFRGS, ele prefere uma iniciativa mais "modesta": oferecer conhecimentos em Desenho Industrial sob a modalidade de uma disciplina de graduação na Arquitetura. "Iniciativa benéfica aos discentes inclinados ao estudo do projeto de produto ou comunicação visual" (WEIMER, 2004). Novamente, esse projeto concretizaria uma expectativa acalentada pelos "artistas técnicos" da geração anterior, de acessar conhecimentos específicos da atividade projetual.

Weimer, no entanto, também não obteve sucesso sem o apoio dos discentes, que não se entusiasmaram com a oferta de uma disciplina de Desenho Industrial optativa, pela inconformidade com o contexto sociopolítico (WEIMER, 2004, p.81) e talvez por ignorarem o potencial da proposta, que ampliava significativamente o campo de atuação profissional. Foi preciso esperar até 1977 para que o ensino formal do Desenho Industrial, na condição de disciplina do curso de Arquitetura, fosse oferecido na FA- UFRGS. 


\section{Considerações Finais}

Sintetizando o processo histórico em foco, a FA-UFRGS foi um espaço privilegiado das iniciativas pioneiras estudadas, o que corrobora a tese de Bozzetti (2004) que identifica a inauguração da faculdade como marco na cultura projetual no Rio Grande do Sul. Apesar de não serem efetivadas, as iniciativas comprovam o empenho por parte de profissionais da área do ensino da Arquitetura em implantar o ensino do Desenho Industrial no RS, assinalando a existência de um ambiente favorável à formação da prática profissional de uma atividade projetual distinta da Arquitetura.

Foram identificados fatores conjunturais sociopolíticos, como a Reforma de 1968 e o descompasso conceitual, que dificultaram o processo da implantação do ensino devido a incipiência da compreensão do Desenho Industrial no cenário local naquele período. Somam-se ainda os fatores específicos, peculiares ao ambiente local, como o desinteresse institucional em oferecer ensino de especialização, a falta de condições de infraestrutura e de recursos humanos.

Os protagonistas das iniciativas pioneiras apresentam características peculiares: são egressos da FA-UFRGS, atuaram no ensino da arquitetura e desempenharam a prática projetual no Desenho Industrial. Cabe destacar a contribuição de cada um. Araújo exerceu uma presença marcante, que se irradia nas esferas do ensino, na prática profissional e na promoção da classe profissional. Sua estadia no ambiente cosmopolita de São Paulo (1966) permitiu-lhe conviver com personalidades como Umberto Eco, Michel Arnoult, Flávio de Carvalho, Lúcio Grinover, Décio Pignatari, Rubens Martins. Vivência que rendeu o intercâmbio de alguns destes expoentes no cenário local. A contribuição de Petzold se ampara na parceria com Bornancini, que o inseriu no meio industrial. Destaca-se ainda na docência, ao compartilhar a cadeira de Composição Decorativa com Araújo (1965-68). Essa experiência o capacitou na estética modernista sob a perspectiva do projeto de produto e da comunicação visual (CURTIS, 2017, p.235). Quanto a Weimer, é indiscutível que sua especialização na HfG Ulm (1966-67) o qualificou de modo privilegiado na atividade projetual. Oportunidade rara no meio local, quando ainda não havia formação específica neste campo de atuação profissional. Por outro lado, atuou em projeto de produto apenas no início da carreira, se desligando da prática projetual e passou a dedicar-se à pesquisa e docência. Araújo manteve vínculo com o ensino de Arquitetura na Uniritter e continuou a carreira na Arquitetura (MARQUES, 2016a). Petzold desenvolveu projeto de produto por mais de quatro décadas, dando visibilidade ao design gaúcho no eixo Rio-São Paulo. Atua no âmbito do ensino de design, proferindo palestras sobre sua prática projetual em vários cursos de Design no Sul. E, quando se pronuncia junto aos discentes sobre o ensino, lamenta não "ter tido a oportunidade de estudar design".

Mesmo que existisse demanda pela formação em desenho industrial no Rio Grande do Sul de meados do século XX, como os "artistas-técnicos" em busca de ensino mais próximo a seus interesses, e as iniciativas enfo- 
cadas, a sua institucionalização tardou em se efetivar. Finalmente, o protagonismo exercido por Araújo e Petzold, embora sem a especialização em Desenho Industrial, obtida por Weimer, foi mais efetivo. Os profissionais apresentados nesse artigo estavam integrados na prática e no ensino da Arquitetura e na prática do Desenho Industrial. A trajetória deles na busca pela institucionalização do ensino do Desenho Industrial não foi bem sucedida nos anos 1960-70, mas gerou as condições para a posterior implantação da cultura local de design como o intercâmbio com expoentes da prática projetual e o reconhecimento e valorização do design rio-grandense.

1 Conforme Freitas (1999:55) nos primórdios do ensino, a cronologia das escolas de desenho industrial indica iniciativas em outras localizações como Minas Gerais (FUMA, 1964), Maranhão (UFM, 1970), Pernambuco (UFPE, 1972), Paraná (UCPR, UFPR, 1975), Paraíba (UFPB, 1978). Porém, optou-se por estabelecer um comparativo estrito com a região sudeste devido a sua supremacia em âmbito industrial.

2 Na origem do ensino de arquitetura no Brasil subjaz uma forte influência do modelo didático-pedagógico da École des Beaux-Arts parisiense, fundada em 1806. Por "padrão federal" compreende-se as disciplinas e seriação adotada pela Faculdade Nacional de Arquitetura (FNA/RJ) e que serve de modelo para o ensino de arquitetura em outras instituições de ensino no país, como o IBA/RS (MELLO, 2016: 154)

3 Impasse que transcendeu o meio acadêmico pois a imprensa local também aderiu a polêmica, conforme Mello (2016: 149).

4 Conforme site da entidade o IAB/RS data de 1938. Disponível em< http://www.iab-rs.org.br/agenda/festa-de-70- anos-do-iab-rs.aspx > Acesso em março de 2018.

5 Grifo nosso, a fim de dar destaque à atualidade desta afirmação, que pode ser enquadrada no âmbito da prática projetual em design, válida no século XXI.

6 Artistas-técnicos, no entender de Bozzetti (2004), significa aqueles estudantes que, em meados da década de 1960, 1970 tinham interesse em desenvolver projeto, mas não queriam necessariamente ser artistas nem engenheiros. Portanto, a arquitetura era a alternativa mais alinhada aos seus interesses projetuais, no ensino formal.

7 Austríaco, arquiteto, pintor, escultor e cenógrafo, representante da arquitetura moderna internacional. Durante o impasse com o IBA foi contratado pela Escola de Engenharia, exerce influência no ensino de arquitetura no Rio Grande do Sul atuando de 1946 a 1951 (MARQUES, 2012, p. 26; MELLO, 2016).

8 Nomes como Mies Van der Rohe, Harry Bertoia, Isamu Noguchi, Pierre Jeanerret, Franco Albini e Florence Knoll (ARAÚJO, 1967 apud MARQUES, 2016a, p. 9).

9 Prédio histórico que se situa no Campus Central da UFRGS, serviu de espaço para o curso de arquitetura antes de ser construída a sede da FA-UFRGS, um prédio modernista, no Campus Central.10 Denominação de desenho industrial no âmbito do ensino da arquitetura no período em estudo (BOZZETTI, 2004:34).

11 José Carlos Mário Bornancini (1923-2008), engenheiro civil, docente na Escola de Engenharia, UFRGS. Desde o final da década de 1950 desenvolve projeto de produto, atuando em parceria com Nelson Petzold a partir de 1962 na indústria rio-grandense (PETZOLD, 2008; CURTIS, 2017). 12 Conforme Currículo Lattes. Disponível em http://buscatextual.cnpq. br/buscatextual/visualizasv.do?id=K4783309U4\#FormacaoAcademicaTitulacao Acesso em março de 2018.

13 Segundo Braga (2016, p.100), Armênio Wendhausen também era sócio da ABDI, assim como Bornancini e Petzold. 
14 Conforme fac-símile do documento manuscrito (1966) cedido às autoras por Petzold (2011).

15 Engenheiro Civil, professor do IBA, catedrático de Sistemas Estruturais na FA-UFRGS (MELLO, 2016: 141).

16 Na pesquisa realizada não foi encontrada nenhuma menção à disciplina Decoração de Interiores, assim considera-se que Weimer se refere a Composição Decorativa, disciplina que constava no currículo de arquitetura durante o período enfocado, e era ministrada por Araújo.

17 Segundo Mello (2016), consta no Currículo (1977) da Graduação em Arquitetura uma disciplina intitulada "Introdução ao Desenho Industrial". Segundo dados obtidos no Currículo Lattes de Günter Weimer, a disciplina foi ministrada por Weimer, de março de 1977 a julho de 1978.

18 Cabe mencionar que a afirmação é uma novidade no contexto da cultura local de atividade projetual, uma vez que tal concepção já havia sido apregoada por Walter Gropius na primeira metade do século XX, Bauhaus/ Dessau.

\section{Referências}

BERED, E. Impressões sobre os acontecimentos ligados à fundação da Faculdade de Arquitetura da UFRGS. Arquitetura UFRGS, 50 anos de História. BONI, F.; CAFRUNI, S. (org.) Porto Alegre, RS: Editora da UFRGS, LIGHT, 2000.

BOZZETTI, Norberto. Design no Sul: uma experiência pessoal, um testemunho. Pensando Design 1, MAGALHÃES, Eliane (et al.) Porto Alegre: UniRitter Editora, 2004.

BRAGA M. (org.). O papel social do design gráfico. São Paulo: SENAC Editora, 2011. BRAGA M. ABDI e APDINS-RJ, São Paulo: Blucher, [livro eletrônico] 2016. Disponível em http://openaccess.blucher.com.br/article-details/19730.

CARA Milene. Do desenho industrial ao design no Brasil: uma bibliografia crítica para a disciplina. BRAGA, Marcos (org.) São Paulo: Blücher, 2010.

CURTIS, Maria do Carmo Gonçalves. O fator interacional no desenvolvimento do projeto de produto: contribuição metodológica de Bornancini e Petzold. Tese (Doutorado)330 f. - Universidade Federal do Rio Grande do Sul, Escola de Engenharia, Faculdade de Arquitetura, Programa de Pós-Graduação em Design, Porto Alegre, BR-RS, 2017. Disponível em <http:// www.lume.ufrgs.br/handle/10183/174412>

FREITAS, Sydney Fernandes. A influência de Tradições Acríticas no Processo de Estruturação do Ensino/Pesquisa de Design. Tese de Doutorado, UFRJ/COPPE, 1999. Disponível em <http://www.posdesign.com.br/artigos/dissertacao_sydney/Corpo\%20da\%20Tese.pdf > FROTA, José Artur; FUÃO, Fernando; LEÃO, Silvia. Claudio Araújo: um depoimento, s/no, Revista ARQTEXTO, p.116, 123, 2000

MARQUES, Sergio Moacir. Fayet, Araújo e Moojen: arquitetura moderna brasileira no Sul, 1950- 1970. Tese (Doutorado) Universidade Federal do Rio Grande do Sul, Faculdade de Arquitetura, Programa de Pós-Graduação em Arquitetura, Porto Alegre, BR-RS, 2012. Disponível em <http://www.lume.ufrgs.br/handle/10183/65665?show=full>

MARQUES, Sergio Moacir. Cláudio Araújo e os primórdios do design moderno no sul. Arquitextos, São Paulo, ano 17, n. 194.04, Vitruvius, jul. 2016a <http://www.vitruvius.com.br/ revistas/read/arquitextos/17.194/6125>.

MARQUES, Sergio Moacir. Adeus Capitán. Cláudio Araújo (1931-2016). Drops, São Paulo, ano 17, n. 107.09, Vitruvius, ago. 2016b <http://www.vitruvius.com.br/revistas/read/ drops/17.107/6180>. 
MELLO, Bruno Cesar Euphrasio de. O urbanismo dos arquitetos: Genealogia de uma experiência de ensino, Tese (Doutorado) 389 f. -Universidade Federal do Rio Grande do Sul, Faculdade de Arquitetura, Pós-Graduação em Planejamento Urbano e Regional, Porto Alegre, BR-RS, 2016. Disponível em <https://www.lume.ufrgs.br/bitstream/handle/10183/151140/001010082.pdf?sequence $=1>$

NIEMEYER, Lucy. Design no Brasil: origens e instalação. Rio de Janeiro: 2AB, 2000.

PETZOLD, Nelson. Vivendo design. Pensando Design.2 BOZZETTI, Norberto; BASTOS, Roberto(org.) Porto Alegre: Uniritter, 2008.

PETZOLD, Nelson. Nelson Petzold: depoimento [maio de 2011] Entrevistadora :Maria do Carmo Curtis, Porto Alegre, 2011, Residência do designer.

PROGRAMAÇÃO PARALELA de DESENHO INDUSTRIAL, 1966. Documento manuscrito, disponibilizado em arquivo pdf por Nelson Petzold em 2011.

WEIMER, Günter. Um depoimento. Pensando Design 1, MAGALHÃES, Eliane (et al.) Porto Alegre: Uniritter Editora, 2004. 